\title{
PARQUE FLUVIAL NA REGIÃO DO VALE MÉDIO TIETÊ
}

\section{Autor:}

Fernando Vicente de Oliveira

\section{Orientador}

André Munhoz de Argollo Ferrão

\section{Instituição:}

Universidade Estadual de Campinas. UNICAMP

\section{OBJETIVO}

Caracterizar a região do Vale do Médio Tietê, em sua ligação entre as cidades de Cabreúva, Itu, Salto e Porto Feliz através do eixo formado pelo rio Tietê, em sua bacia pertencente ao Sorocaba Médio - Tietê, no Estado de São Paulo, Brasil, como um parque fluvial, no modelo do Parque Fluvial do rio Llobregat, Catalunha, Espanha, enquanto uma potencialidade e ferramenta para o uso do planejamento e da ordenação territorial assim como um veículo de desenvolvimento regional. A questão de partida é como um parque fluvial pode relacionar as iniciativas que afetam a população local e se os parques levam em conta as representações sociais e como o seu processo de execução, contempla a paisagem e patrimônio.

\section{INTRODUÇÃO}

A região do Vale Médio Tietê, cuja ligação entre as cidades de Cabreúva, Itu, Salto e Porto Feliz tem o rio Tietê como eixo, em sua bacia pertencente ao Sorocaba Médio - Tietê, no Estado de São Paulo, Brasil, possui ao longo de seu percurso um patrimônio diversificado, que é valorizado como bem cultural. Este patrimônio constituise de um legado, material e imaterial, com edificações, fazendas, festas, parques e paisagens que no transcorrer das últimas décadas tem merecido destaque pelos órgãos de preservação, assim como pelos meios científicos, que estudam a região. 
Estas cidades tiveram seus primeiros assentamentos já desde o século XVII, com dinâmicas diferenciadas de cultura e economias, alterando a paisagem significativamente.

Em seu início era entreposto de bandeirantes, passando por uma forte economia de cana-de-açúcar e depois do café, sendo por fim ocupado para o setor industrial e de serviços. Todos estes períodos são marcados pela presença cultural que marca a sua paisagem expressivamente. Os municípios estudados ocupam a área deste trecho da bacia, algumas tendo seus centros edificados às margens do rio. $O$ que configura espacialmente as cidades como as antigas fazendas é o espaço formado ao longo do eixo do rio.

Hoje, os bens culturais que se formaram, de todas estas cidades, graças à conexão do rio, são valorizados pelo ponto de vista histórico, estético e simbólico, mas alguns se encontram ameaçados pela especulação, correndo o risco de serem descaracterizados ou, até mesmo, desaparecerem. Para isso é fundamental examinar de maneira mais aprofundada e multidisciplinar, as particularidades compositivas, materiais e imateriais de cada um dos patrimônios, apreendendo seus elementos estruturadores na lógica de um parque fluvial.

\section{INFORMAÇÕES UTILIZADAS, RESULTADOS E REFLEXÕES OBTIDAS: UMA NOVA VISÃO PARA O RIO TIETÊ.}

Para a área a ser analisada enquanto um parque fluvial este trecho de sua bacia conta com uma série de sete parques já constituídos: Estrada Parque APA Cabreúva-Itu; Parque dos Varvitos, Itu; Parque Rocha Moutonée, Parque das Lavras, Parque do Lago e Memorial do rio Tietê, todos em Salto e Parque das Monções, Porto Feliz. Além destes parques há a potencialidade de criação de um parque dos Matacões, entre os municípios de Salto e Itu. Estes parques além do caráter histórico da região, contam com santuários de natureza ricos tanto em fauna e flora, como em vestígios geológicos, o que será indicado nesta proposta de parque fluvial. 
Ab'Sáber(2003) já distingui o canyon do Tietê à jusante de Cabreúva e à montante de Itu como um importante desfiladeiro, internamente revestido por uma densa floresta tropical biodiversa. A novidade reside no fato que nas poucas vertentes onde afloram matacões ou lajes de granito existem remanescentes minirrelictos de mandacarus, indicando que cactáceas precederam as florestas tropicais da região.

No campo do patrimônio natural há a definição e identificação destes elementos ressaltados por Carpi Jr. (2010) enquanto formas de percepção do território, que destaca a valorização do geopatrimônio regional, através dos seguintes elementos naturais do Vale do Médio Tietê: $O$ destaque, segundo o autor, também fica por conta do canyon, como patrimônio natural fundamental. Destaca-se aqui que além deste elemento de interesse ambiental, formado pelos matacões, morros, grutas, cobertura vegetal variada, há também o interesse histórico como as fazendas e cidades.

Também como justificativa para as cidades e o espaço estudado, Toscano (1977), destaca os seguintes elementos:

- A forma geográfica de o rio percorrer este trecho encaixado em um canyon, área de grande beleza cênica.

- Área que ainda sofre os efeitos de poluição, mas apesar disto, mantém seu valor paisagístico.

- Diversidade de fauna e flora de Mata Atlântica e Caatinga. A região estudada pertence a uma área de APA (área de proteção ambiental).

- Potencial turístico evidenciado pelas fazendas, campings, parques, patrimônio industrial construído como a Usina Hidrelétrica São Pedro e manifestações culturais como romarias e cavalgadas.

- Cidades que já são estâncias turísticas como Salto e Itu e outras que têm a potencialidade de serem, pelo seu patrimônio arquitetônico e cultural da região como Cabreúva e Porto Feliz.

- Os matacões que se potencializam como área para criação de parque. 


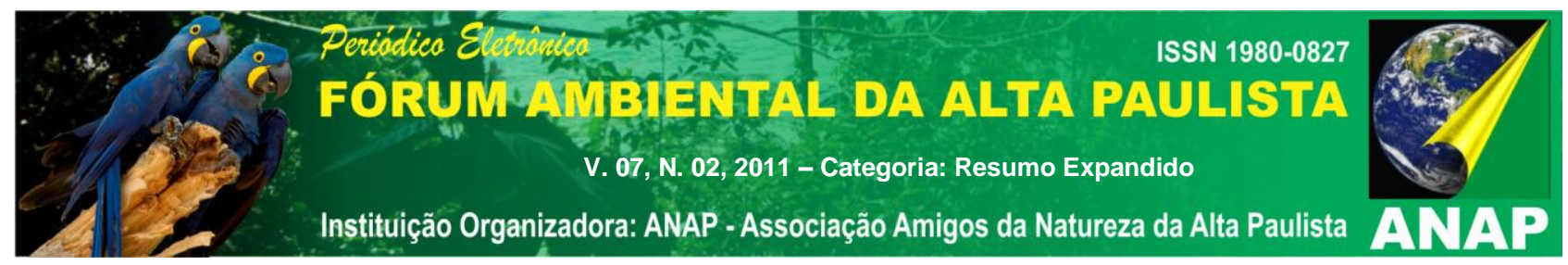

As cidades que compõem a bacia do rio Tietê no trecho estudado se comparam com as do rio Llobregat, Espanha por serem de porte médio, sujeitas a pressões, tiveram um passado de apogeu que ocorreu por diversas atividades econômicas e tinham o desafio de propor uma recuperação para agregar à sociedade que vive ao longo deste curso d'água, uma nova proposta do olhar sobre sua paisagem. A Espanha tem operado transformações radicais em seu tecido urbano, requalificando áreas centrais das cidades, áreas portuárias e antigas zonas industriais, entendendo que são regiões, de modo geral, dotadas de boa infra-estrutura e, no entanto, subutilizadas. Muitas dessas áreas envolvem vales e rios, cujas várzeas foram sendo gradativamente ocupadas e participam do escopo de requalificação urbanística.

Segundo Sabaté (2001) o valor da paisagem cultural na Catalunha, Espanha, tem uma tripla origem: no trabalho da administração pública sensível à questão, uma reflexão acadêmica por parte das universidades e por último às pessoas envolvidas com o território em questão, os amantes do patrimônio local. O sucesso dos projetos se deve ao trabalho em conjunto destes três grupos. Da mesma maneira se apreende esta conexão para o rio Tietê e por essa razão o seu estudo comparativo de forma a confrontar sua lógica de configuração, desenho e forma.

A pesquisa desta maneira reconheceu com os estudos realizados algumas questões:

- um trecho fluvial mais apreciável, preservando um cinturão verde;

- atividades de comércio, serviços e indústrias contemporâneas que reconhecem sua responsabilidade ambiental;

- uma rede de locais especializados de interpretação local e de museus de percurso que incluem centros de visitação e orientação temáticos. Eles narram a história do Tietê, desempenhando papel educativo;

- reutilização das antigas fábricas, fazendas e outros elementos arquitetônicos. Edifícios renovados que abrigam uma nova gama de atividades - hotéis e centros de conferência, escolas e instituições de ensino, residências para as 
comunidades locais, pesquisa de novas tecnologias espaços de escritórios, todos mantendo o desenho e o caráter do assentamento histórico; e

- uma rede viária requalificada associada com o rio e restabelecida como uma rota turística cênica.

\section{PROPOSTAS AO DEBATE E REFLEXÕES}

1. discutir o potencial ambiental de um parque fluvial através de sua legislação, estudos comparativos e de desenvolvimento regional como fator de recuperação de espaços degradados;

2. relatar a experiência do Brasil e da América Latina com os projetos de parques fluviais implantados em seus rios, enquanto uma solução de áreas degradadas.

3. discutir o conceito de parque fluvial;

4. considerar e identificar as fragilidades (ameaças) e potencialidades (oportunidades) dos parques fluviais, enquanto inclusão social;

5. analisar como inter-operacionalizar o patrimônio e os parques existentes na Bacia do Sorocaba Médio-Tietê, como resignificação de espaços público; e

6. recomendar o parque fluvial no rio Tietê, entre as quatro cidades propostas no estudo de caso.

\section{REFERÊNCIAS}

AB' SÁBER, Aziz Nacib. Os domínios da natureza no Brasil: Potencialidades paisagísticas. São Paulo: Ateliê Editorial. 2003.

CARPI JR., Salvador. Paper do VI Seminário Latino Americano de Geografia Física da Universidade de Coimbra, Portugal, maio 2010.

SABATE, Joaquim et al. Projectant l'eix del Llobregat. Paisatge cultural i desenvolupament regional. UPC e MIT 2001.

TOSCANO, João Walter. Diagnóstico Geral da Cidade de Itu para a implementação de um programa de ação cultural. São Paulo: CONDEPHAAT, 1977. 


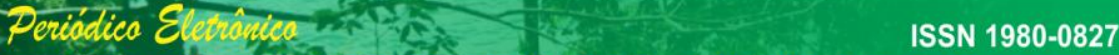

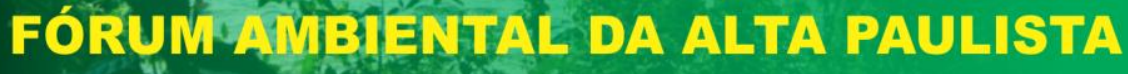 \\ V. 07, N. 02, 2011 - Categoria: Resumo Expandido}

Instituição Organizadora: ANAP - Associação Amigos da Natureza da Alta Paulista

ANAP

UNESCO, Patrimônio Natural, disponível em

http://www.unesco.org.br/areas/ciencias/areastematicas/patrimonionatural/index html/ mostra documento. Acesso em 10/04/07 